\title{
Nepal's Free Health Care Policy in Practice: Perspectives from Community Stakeholders, Providers and Users of Health Services in Myagdi District
}

Shiva Subedi

\begin{abstract}
Government of Nepal has introduced Free Health Care Policy (FHCP) through different tiers of health delivery system in 2007. With the objective of understanding the perspectives of community stakeholders, health service providers, and the services users towards free care policy, a qualitative-quantitative study was conducted in selected communities of Myagdi district from December 2010 to January 2011. Although the majority of user group thought that free care service is good but only two-third of them had received free care. Shortage of free essential drugs at health facility centers, absence of health workers and lack of clear information about free services or counseling on free services available at health facility centers are the most repeated issues raised by the service users. Similarly, the service providers had similar experiences and perceptions on FHCP. The majority of the community stakeholders also had positive perception on this implemented policy. They have observed that many facilities had shortage of drugs and people are not having free health care. Many health facilities lacked interaction on FHCP, and service users did not have equitable access to the services provided. Overall, though the free care was perceived to be good policy, its satisfactory implementation remains one of the challenges. Many of the areas relating to service delivery need to be strengthened. A reliable supply system of drugs and its regular monitoring mechanism can ensure the effective implementation of free health care services.
\end{abstract}




\section{5| Shiva Subedi}

Keywords: Free health care policy, perception, community stakeholders, Myagdi, Nepal

\section{Introduction}

Since 2007, Nepal has adopted a policy of free health care services to the poor and vulnerable citizens attending primary health care centers and district hospitals (up to 25-bed capacity) as a targeted exemption provision from 2007; additional free outpatient services were also offered to the same groups from the district hospitals in 35 districts on the basis of lowest ranked Human Development Index from 2008. Then after six months, a universal free health care provision was implemented at Sub-Health Post and Health Post level. A second universal program commenced in January 2008 aimed the provision of free essential health care services to all citizens. Similarly, being committed with the spirit of the Interim Constitution of Nepal 2007: "access to basic health services as a fundamental right of each and every Nepali citizen" the Ministry of Health and Population has endorsed free health care services provision as an ambitious socialistic approach from January 2009; to meet the demand of rural population, poor and needy people. Now, there are no any charges for registration and dispensation of listed 25, 32, 35 and 40 sorts of items distributed to people at Sub-Health Post (SHP), Health Post (HP), Primary Health Care Centre (PHCC) and at District Hospital (with less than 25 beds) level respectively across the country (MoHP, 2009).

Primary Health Care Revitalization Division(PHCRD)has made some provision of fund for the treatment of all patient related to target groups at central, regional, sub-regional and zonal hospital. PHCRD has also made an amendment in the policy by adding the number of distributed medicine from 32 to 36 at HP, 35 to 58 at PHC and 40 to 70 items at hospital level (MOHP, 2014).

Universal coverage reform is one of the four current concerns of PHC reforms' agenda (universal coverage, service delivery, leadership and public policy) mainly to improve health equity, and effective response to the health challenges of today's World (WHO, 2008). As a financing strategy, this program intends to bolster equity since cost has always been a critical barrier for accessing health care 


\section{6| Shiva Subedi}

(MLI-2011/10). Despite a signatory made in the historic Alma-Atta Declaration back in 1978, overall implementation of the policy has often left much from the desired level to "Health for All". As the idealistic deadline of the MDGs, 2015, looms closer, some countries are calling for fees abolition (Ridde, Messen, Kouanda, 2011).

The approach "Free Health Care Policy" has been a 'buzz' phrase in the public regardless whether they are benefitting or not. To date, there, has not been any study conducted on policy implications being closed up to the micro-level, in the community level. However, a couple of researches have been carried out at national level. Therefore, it is important to understand the overall situation of the implemented policy whether or not the policy is meeting defined objectives. How has the policy been functioning in village level in practice taking into account scarce resources ? Are all people able to have access to these free health care services with quality?

One of the main objective of this study is to discuss findings of the first two years (2009-2010) of implemented universal free health care services in a rural district, western part of Nepal. This article also examines the status of service utilization pattern, and discusses about some opportunities and practical issues explored at the community level that come to draw the attention of the study.

\section{Data and Method}

The study sites were purposively selected two VDCs. Gurjakhani, a rural village and Arthunge located in urban area of Myagdi district. Out of total 97 households (total population: 564) visited, one representative aged between $15-85$ years who had visited a nearby government health facility at least once in the last 12 months, was selected for interview. The first "service users group" consisted of 78 people ( $\mathrm{M}=25$ and $\mathrm{F}=53)$. The second group "service providers" consisted of three government health facilities such as: Sub-Health Post (SHP) located at Gurjakhani, District Hospital in Beni (urban) and a Health Post (HP) located in Takam Village, a semi urban area. At health facilities, observation visit was carried out using semistructured checklist for the stock situation of free distributing drugs, staff availability, and patient record. The third group "stakeholders" consisted of 24 respondents $(M=17$ and $F=7)$ from the two selected 


\section{7| Shiva Subedi}

VDCs. Geographic location of the sites are presented on the map (Figure: 1). A focus group discussion (FGD) was conducted with the user group. Key Informant Interview (KII) was carried out with the 16 service providers $(\mathrm{M}=9$ and $\mathrm{F}=7)$ and 24 stakeholders. Both qualitative and quantitative data were collected and analyzed. Data were collected from December 2010 to January 2011.

\section{Map of Study District and Area (Figure: 1)}

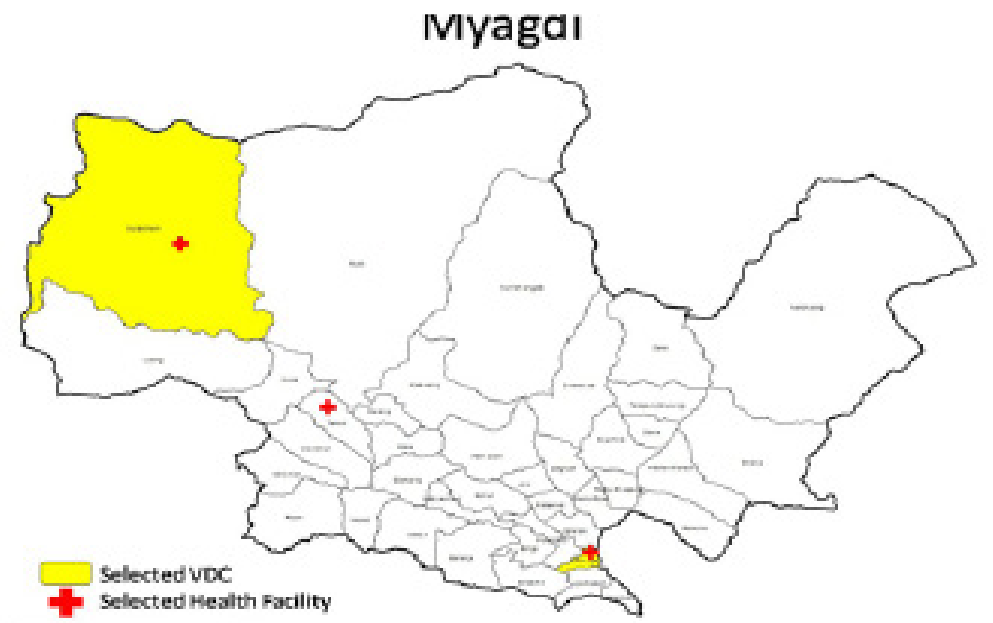

\section{District Profile}

Myagdi district lies in the Western Development Region of Nepal. The total population of the district is 113,641 with 41 Village Development Committees (CBS, 2011). Though Magars are predominant ethnic group (45\%) in Myagdi, this is a home place of diverse social groups--Dalit (18\%) and Chhetri (17\%) DDC, 2009). Of the 41 VDCS, only six constitute one-third of the total population of the district and these areas are concentrated in the southern part of the district. About one third of the VDCs do not have access to a motor-able road; hence travel on foot is the only means available in these areas (Thapa, Subedi, \& Shrestha 2013). The average literacy rate of the district is just 56 (male 67, female46) percentage (DDC, 2009 ) as it was 22.1 percentage in 1981 , according to CBS, 2001, The "Human Development Index"(HDI) of this district is 0.49 (UNDP, 2014).As regards health institution, Myagdi district has one 15-bed hospital, one Primary Health Care Centre, 12 Health Posts, and 27 Sub-Health Posts. 


\section{Results}

\subsection{Trend of Service Utilization:}

According to the OPD register, a total of 9757 patients had visited to district hospital (urban) in fiscal year (F/Y) 2062/063 and 15555 patients visited in 2066/067 F/Y. Similarly, the number of patients was 423 at Gurjakhani SHP in F/Y 062/63; which is increased to 971 by $\mathrm{F} / \mathrm{Y} 066 / 67$.

\section{Table 1: Trend of Service Utilization}

\section{Fiscal Year( $(\mathrm{Y} / \mathrm{Y})$}

$2062063(2006)$

2063/064 (2007)

$2064 / 065(2008)$

2065/066 (2009)

2066/067 (2010)

No of Client Registered in OPD Section, by Geography

\section{District Hospital}

9757

14752

10807

13512

15555

\section{Gurjakhani SHP}

423

469

424

830

971

Source: Field Survey, 2011

\subsection{Availability of Listed Drugs:}

In regards to availability of free distributing drugs,33out of 40 items were available at district hospital, and 19 out of 25 items at Gurjakhani SHP. Similarly, only 22 out of 32 listed drugs were obtainable at Takam Health Post at the time of field visit.

\subsection{Provision of Free Health Services and Service Users:}

Most of the respondents $85.2 \%$ (35/78) had received free health care services from SHP, while less than half of respondents $43.2 \%$ $(16 / 37)$ reported that they had visited to district hospital and used free care service. However, $35 \%$ (27/78) of the respondents didn't have an access to free care in the district.

"Only paracetamol is available at hospital; doctor prescribes the drugs to take it from dispensary but we couldn't get from there 
accordingly," said, 47 years' literate male from urban area/HHs.

Table 2: Provision of Free of Cost Distributing Listed Drugs

Place Service Users' Response on Free of Cost Medicines

$$
\text { Yes }(\%) \quad \mathrm{N} \quad \mathrm{No}(\%) \mathrm{N}
$$

Gurjakhani $\quad 85.2 \% \quad 35 / 41 \quad 14,8 \% \quad 6 / 41$

(Rural)

Authunge $\quad 43.2 \% \quad 16 / 37 \quad 56.8 \% \quad 21 / 37$

(Urban)

\section{Total $\quad 65.3 \% \quad 51 / 78 \quad 34.7 \% \quad 27 / 78$}

Source: Field Survey, 2011

4.3.2 Opportunities from free health care policy: Regarding the perceptions of users about free healthcare services, some of the respondents reported that there are several positive changes. More than one third38.3 (30/78) said that it was effective in health problems like fever, diarrhea, injuries, common colds and skin infections and around one fourth (19/78) respondents appreciates the free service. During the process of household interview, an illiterate dalit male, from urban area mentioned:

"Free healthcare approach is good and important, we dont have to pay even 5 rupees for registration,"

4.3.3 Issues on access to free care services: There were also complaints regarding equal opportunities of service as users with links to political power, relatives and places, recommendation from management committee for their familiar persons were reported to get preferential treatment. Regarding discrimination, a 61 years' male, literate Brahmin respondents from urban area states that:

"Health workers provide free of cost drugs to the person coming from power, next for their own relatives then comes our turn,"

\subsubsection{Perspective from Health Service Providers}

Existing opportunities and expectation of public towards FHCP: 


\section{0| Shiva Subedi}

With the endorsement of free health service. Around two-third 68.8\% $(11 / 16)$ of the informants expressed of having good opportunities from this provision and mentioned:

In the process of KII, many expressed the opinion that the approach is good, there are many advantages of FHCP and clients don't have to pay for simple treatment, poor people are getting more benefits from it. However, it has been difficult to address the increased hope of public towards free service within limited listed medicines. Issue in identifying criteria for poor and ultra-poor: During the KII, respondents said that challenges of implementation associated with free program include unclear criterion in guideline for distinguishing between poor and ultra-poor target groups.

Issue on access to listed drugs at health facility: Despite widespread dissemination of message on free of cost drugs being available, $62.5 \%(10 / 16)$ health providers were often facing the challenges of essential medicines being stock out. One of the service provider's expression about the availability of drugs was that

"As I experienced, patients mostly come with illnesses like common cold, diarrhea case...sometimes existing provision of essential medicine doesn't meet the seasonal health problems such as typhoid, pneumonia, common cold, diarrhea cases and other needy treatments for disease". Similarly, public would benefit if the government added some of the essential drugs including antibiotics for common diseases like typhoid and heart related problems.

Issue in processing of action plan with budget: At central level, there is a system to devolve an action plan with budget to every district at the beginning of new fiscal year. A senior government official (DHO) said his experience like this: this F/Y 2067/068, Primary Health Care and Revitalization Division delayed in releasing the budget and action plan. So, it has been too late in procurement process for essential drugs from district.

Issue of access to right information: Patients who come for the free services say that they are not receiving adequate and correct information regarding free health care provision. Over two-third $(12 / 16)$ of the respondents mentioned that there is a dearth of right 


\section{1| Shiva Subedi}

information about the program. Staff working under pressure: Over burden of work was identified as one of the major pressing issues. More than $80 \%(13 / 16)$ of the respondents reported that they were overworked due to insufficient manpower at health facilities. During the KII, a female health worker shared her expression and mentioned:

"As far as I am experienced, it is being very difficult to maintain recording and monthly reporting under this program. Only 2 out of 5 sanctioned posts have fulfilled at this health facility".

Rational use of medicines: In general, unnecessary demand, over use, misuse and leakage of drugs, poor consultation with senior health worker were found likely to increase careless use of medicines and free care services. In the process of KII, District health officer mentioned:

"There is also an equal chance of being over used, misuse and leakage of drugs at district level unless and until a mandatory standard crosscheck system has been established". Another health worker from rural area shared her opinion: "Clients demand lots of medicines for other family members' health problems by stating they come from very remote areas it is difficult for us to deny their request".

Good approach but weak implementation: All the service providers viewed that the intention of this policy was good and marginalized groups were getting benefit of it as they didn't have to pay money even for registration. There is a good impact on services such as OPD and delivery. However, poor local resources, inadequate provision of drugs, quality, weak performance of health management committee, less supervision activities, not regular training for health staff were identified by many of the respondents as weaknesses.

\subsection{Perception from Community Stakeholders}

Opportunities from the services: Most of the respondents 70.8\% $(17 / 24)$ recognized the free healthcare service has some advantages. It benefits elderly, Dalit, poor and chronically ill people. During the KII, many stakeholders mentioned:"some people are saving money; and that is being used in buying notebook, pens for their children because of the free of cost registration and drugs". Despite that, 


\section{2| Shiva Subedi}

few have not had similar experiences so they noted:"Public are not getting service as expected".

Perceived Problems: Despite the willingness to use free health care service has increased, lack of adequate stock, understaffing and absence of senior health worker, not adequate counseling always make people unhappy. In the process of KII, two male respondents reported that 'in most cases, we don't get needed drugs except paracetamol from our SHP because health staff tells us in this way: "Sometimes we don't have these medicines therefore you need to go to private pharmacy outside". Similarly, 13/24 respondents reported their experience of observing health facilities not having adequate stock of medicines.

A sense of discrimination to service seekers has been felt by respondents. The public complains to us that nepotism is in practice; if a relative of patients is working at the health facilities they are likely to get services immediately. Otherwise people are referred to visit to private clinics. Many of the respondents reported that it is apparent that an awareness and interaction program among service providers, users and public at community level is needed there. During the KII, a female, an NGO activist mentioned:" There has been a discussion on the issue of information between non-governmental staff and government service providers at village level because our NGO's staff are providing information to the community about free healthcare. When people visit to health facilities they don't get free listed drugs as per policy.

\section{Discussion}

In Nepal, the impact of the free health care program has not yet been officially evaluated. The results are based on perspectives drawn from the community stakeholder, users and providers of implemented free services. With an endorsement of free care service, it has presented some positive signals in the community. At district, there has been a gradual increase on service utilization at rural as well as urban over a period F/Y 2065/2066 to 2066/2067. Similarly, the findings also highlighted that service used by Dalit community increased and the services utilization at HPs and SHPs proportionally is higher than Janajatis. In case of Madhesi user no 


\section{3| Shiva Subedi}

significant change followed, and slightly increased in Muslim users (MoHP/RTI/CARE Nepal, 2009). However, a STS study concluded that the number of receiving free health services has markedly increased over time at all health facility levels. For HPs and SHP there has been a small increase for each year since 2008/2009. For PHCCs and Hospitals there was a large increase between 2009/2011 in compared to past years 2008/2009 (MoHP/NHSSP, 2011).

With respect to awareness, $90 \%$ of outpatients were aware on free health service (MoHP/NHSSP, 2011). But this finding shows that one third 32\% (25/78) service users were known about free healthcare in study area. Client reporting reasons were a precondition for receiving the services $(73 \%)$, required drugs were not on the list of essential drugs $(17 \%)$, and the facility had run out of free drugs (11\%) (MoHP/NHSSP, 2011).If we see the financial investment for the free care services, health facilities receive a fixed volume of essential drugs and funds to cover the cost of treating patients. Sub-district facilities (PHC, HP, and SHP) receive Nepalese Rupees (NRs) 10 (around US \$ 0.13) and district hospitals receive NRs 25 (US \$ 0.33 ) per patient. The policy is functioning to a large degree, but with continuing constraints to staffing and drug availability (Witter, Khadka, Nath, \& Tiwari, 2011). According to stakeholders, nevertheless, it has also found that people have had an opportunity of getting at least some simple medicines -- little money saved by public from registration fees -- and now that is being used for buying notebook- pens for their children-and to other essential domestic purposes. This literature, however, shows that: on the whole, $86 \%$ service users favored the statement that the free drug program was beneficial to the disadvantages groups, and majority of the service provider and stakeholders have had the same experience. Similarly, nearly two-third (62\%) informed that free distributing essential drugs had met their needs (against 24\% who didn't agree). Despite that, procurement and supply capacity at district and below levels was considered inadequate because of lack of trained logistic personnel, frequent staff transfers. Health workers had complaints that due to removal of registration fee, people do not keep their previous prescription (ticket) and fetch drugs for stocking purpose at home (NPCS, 2012). These findings of this study concur with the statement 'mismanagement of free drugs and supply became a head line of newspapers in Nepal' published in journal. It ranged from the 


\section{4| Shiva Subedi}

sale of free drugs in private medical shop to wastage of drugs in the store of health facility (Gurung,2009).

An initial rapid assessment study done by GIZ/MoHP, concerned over the issues on budget unlikely to meet full need of public in the context of accessible free services (Hachette, 2009). Nepal has taken to user fee removal is similar to a number of other countries, focusing on maternal and primary care and blending input-and output-based funding. Sustaining and merging these two free care policies will be the next challenge(Witter et al., 2011).At national level, resources and administrative capacity tied with strong underlying needs for health services created serious challenges to the government of Nepal (Powell-Jackson, Morrison, Tiwari, Neupane, \& Costello, 2009). Therefore, the potential barriers to basic free health services are not only due to fees at health facilities, but are attributed to many other factors such as unreliable system of supplying drugs in remote part, stock out of drugs, understaffing and quality of services.

\section{Conclusion}

This study has shown that respondents' perspectives of free health service delivery provide valuable insights that could help to make aware of existing implemented system at district level. The utilization of services has gradually increased in all health facilities, but more attraction has drawn toward policy from rural part rather than urban site. In addition, there are experiences that service users, and service providers and community stakeholders are perceived to have some advantages with cross-cutting benefits of this policy such as health, economic and social welfare. It is, however, likely that the dissatisfaction has increased with users in terms of quality of services due to unavailability of drugs, inadequate human resource, awareness and interaction among people. The providers identify some of the challenges to include services under resourced capacity, poor management of staff and gap in information for the free health services, and need for more investment especially for drugs to address the increasing public demand. Similarly, the stakeholders were concerned about the barriers to implemented services such as unreliable supply of drugs to remote area, unmet seasonal demand of essential medicines, unequal services due to influence of relationship with health staff. It could be suggested to implementers 


\section{5| Shiva Subedi}

to have effective interaction with public; regular supply of drugs and systematic recording for OPD patients based on ethnic code. Despite the challenges, free health care policy seems to be a milestone for primary care since there is limited health insurance scheme in Nepal.

\section{Acknowledgements}

I would like to express my especial thanks to the Professor Chaitanya Mishra and Professor Madhusudan Subedi for their supervising my dissertation which was submited at the Central Department of Sociology/Anthropology, TU, Nepal. I have used data from data work. Similarly, I am also grateful to Dr. Shyam Thapa for his continuous guidance and valuable suggestions.

\section{References}

CBS (2012). National Population and Housing Census 2011(National Report), Kathmandu, Government of Nepal: Central Bureau of Statistics

DDC (2009). District Profile: Myagdi: Myagdi District Development Committee's.

Gurung, G.(2009). Free Health Care Policy in Nepal: Recent Trend and Challenges. Kathmandu, Nepal: View Points. J Nepal Health Research Council. Oct 7(15), 138-9.

Hachette F.(2009), Free Health Care Services in Nepal: Rapid Assessment of the Implementation and Per Patient Expenditure, GTZ/GFA Consulting Group, DoHS, Nepal, Hillside Print.

Powell-Jackson, T., Morrison, J., Tiwari, S., Neupane, B., \& Costello, A. M. (2009). The experiences of districts in implementing a national incentive programme to promote safe delivery in Nepal. BMC Health Services Research, 9(1), 97.

MLI (2011). Nepal country Spotlight: Ministerial Leadership

Initiative.Reducing Financial Barriers to Reproductive Health Care Nepal Spotlight.Aspen Global Health and Development.

MoHP (2014). Operational Guidelines for PHCRD Program of Nepal. Kathmandu:Primary Health Care Revitalization Division,MoHP, PP. 60-64.

MoHP/NHSSP(2011).Service TrackingSurvey(STS)-2011.Katmandu 
Nepal: Ministry of Health and Population/ Nepal Health Sector Support Project, Government of Nepal.

MoHP/RTI/CARE Nepal (2009).Health Sector Reform Support Project (HSRS Report).Assessing Implementation of Nepal's Free Health Care Policy, Third Trimester Health Facility Survey- 2009, December, MoHP/RTI/CARE Nepal. No. 2.17-12-09.

MoHP (2009).Health Sector Gender Equality and Social Inclusion Strategies.Kathmandu: Ministry of Health and Population. Dec.2009.

MoHP (2008).Operational Guidelines with Amendment: National Free Health Care Program Government of Nepal. Kathmandu: Ministry of Health and Population.

NPCS (2012).Evaluation Report on Essential Drug Procurement and Distribution Program under Free Health Services. Kathmandu: National Planning Commission Secretariat (NPCS).

Ridde V., Messen, B., Kouanda, S.(2011). Selective Free Health Care in Sub-Saharan Africa: An Op p o r t u n i t y for Strengthening Health System? Santepublique.

21786740(PubMed).2011.23(61-7).

Thapa, S., Subedi, S.\& Shrestha, B. (2013).Mobilizing Medical Shops to Increase Access to Medical Abortion in the Myagdi District of Nepal:An Assessment Report. Kathmandu, Ipas Nepal.

UNDP (2014) Nepal Human Development Report, Kathmandu: Print Communication Pvt. Ltd. PP. 15.

WHO (2008). The World Report: Primary Health Care Now More Than Ever, World Health Organization. Switzerland. Geneva:WHO

WHO (2007). The Role of Ethics in the Rational Use of Medicines. Series No.46. New Delhi, Technical Publication, Regional Office for South -East Asia.

Witter, S., Khadka, S., Nath, H., \& Tiwari, S. (2011). The national free delivery policy in Nepal: early evidence of its effects on health facilities. Health Policy and Planning, 26(Suppl. 2), ii84-ii91. http://doi.org/10.1093/heapol/czr066 